\title{
Analysis on Absorption Sound Acoustic Panels from Egg Tray with Corn Husk and Sugar Cane
}

\author{
Masiri Kaamin, Nur Fadzly Md Zaid, Mohd Effendi Daud, Rosdi Ab Rahman, Hairul Mubarak \\ Hassim, Nor Baizura Hamid, Mardiha Mokhtar
}

\begin{abstract}
In the contemporary world, one of the areas that have gained growing attention entails sound control. The motivation has been to respond to the increasing demand to improve sound waves in various contexts. One of the sound absorbing agents entails natural fiber, a platform that has led to the growing development of sound absorbers. Hence, this study's central purpose is to examine the potentiality of sound absorber panels developed from materials such as egg trays with corn husks, egg trays with sugar cane, and egg trays combined. For the selected materials, two tests that are implemented include reverberation room test towards achieving noise reduction coefficients (NRCs) and the impedance tube test - towards achieving the sound absorption coefficients (SACs). For the impedance experiment, findings indicate that the frequency of the absorption values ranges from $0 \mathrm{~Hz}$ to $1000 \mathrm{~Hz}$. For the respective forms of the acoustic panels, the SAC values are seen to be 0.9600, 0.9700, and 0.8900; findings that are achieved under low-frequency conditions. In relation to the case of $\mathrm{NRC}$, the values obtained for the selected panels include 0.5500, 0.5900 , and 0.5000. Indeed, the absorption aspect is seen to be pronounced when the experimental platform entails a combination of egg trays with sugar cane stacks. Regarding the results gained from the case of the reverberation room test, the echo time is likely to be shortened by the acoustic panel. Whereas the maximum time for the egg tray panel is observed to be 4.800 seconds, the case of an empty room depicts a maximum of 6.280 seconds. For the egg tray panels with corn skins and sugar cane, the results point to the maximum times of 3.990 seconds and 4.210 seconds respectively. Hence, it is concluded that the egg tray panel with corn husks depicts lower NRC values. Overall, it is evident that the three materials exhibit a promising state of eco-friendliness, complemented by the affirmation that in the market, they are easily available.
\end{abstract}

Keywords : Sound, Corn husk, Sugar cane, Egg tray.

\section{INTRODUCTION}

Every human being on this earth will not escape the noise

Revised Manuscript Received on July 22, 2019

Masiri Kamin, Department of Civil Engineering, Center for Diploma Studies, Universiti Tun Hussein Onn Malaysia, Johor, Malaysia,

Nur Fadzly Md Zaid, Faculty of Technical and Vocational Education (Civil Engineering), Universiti Tun Hussein Onn Malaysia, Johor, Malaysia.

Mohd Effendi Daud, Faculty of Civil and Environmental Engineering, Universiti Tun Hussein Onn Malaysia, Johor, Malaysia.

Rosdi Ab Rahman, Department of Mechanical Engineering, Center for Diploma Studies, Universiti Tun Hussein Onn Malaysia, Johor, Malaysia.

Hairul Mubarak Hassim, Department of Mechanical Eng., Center for Diploma Studies, Universiti Tun Hussein Onn Malaysia, Johor, Malaysia.

Nor Baizura Hamid, Department of Science and Mathematics, Center for Diploma Studies, Universiti Tun Hussein Onn Malaysia, Johor, Malaysia.

Mardiha Mokhtar, Department of Civil Engineering, Center for Diploma Studies, Universiti Tun Hussein Onn Malaysia, Johor, Malaysia.

[7]. The sound circulation is from the form of gas medium, fluid or density that can produce longitudinal waves [8]. Strong sound waves can cause a phenomenon of noise. This is because the sound source is generated from the human environment, such as the use of unmanaged equipment, industrial activity and construction. This leads to discomfort and discomfort among the community.

Sound disturbances can have a negative impact on humans. Research from Sigh \& Dever, 2004 sound can also cause people to experience problems such as annoying and unpleasant feelings, loss of hearing senses, extreme stress and more. Sound absorption and sound insulation can control the problem. Nowadays, sound absorbing material has been created with various shapes, colors and sizes. Normally, the industry will renegotiate sound absorbers comprising synthetic materials such as glass or mineral fibers. Awareness of safety and health issues has been increasing at present.

The existing sound absorbers on the market are manufactured from materials based on fiberglass materials. Materials containing glass fibers may have adverse effects on human health, particularly in the lungs and eyes [15]. In addition, the absorption of sound absorbers from synthetic fiber materials is expensive and ineffective despite showing good results in absorbing sound [6].

This has led many studies to the potential use of environmentally friendly materials and consumers. Among the studies carried out on natural materials or native fibers used as sound absorbers are wood [13], rice straw [14], wheat straw [10] and bamboo [4]. The cost of production is also seen to decline significantly when environmentally friendly material is used. This outcome is informed by the assertion that the material is safe and easily available for consumer use. Table 1 (below) offers a comparative analysis between glass fibers and natural fibers.

Published By: 
Table I: Comparison between natural fibers and glass fibers (Wambua, J. Ivens, \& I. Verpoest, 2003)

\begin{tabular}{|c|c|c|}
\hline & Natural Fibers & Glass Fibers \\
\hline Density & Low & $\begin{array}{c}\text { Twice of natural } \\
\text { fibers }\end{array}$ \\
\hline Cost & Low & $\begin{array}{l}\text { Low, but higher } \\
\text { than natural fibers }\end{array}$ \\
\hline Renewability & Yes & No \\
\hline Recyclability & Yes & No \\
\hline $\begin{array}{l}\text { Energy } \\
\text { Consumption }\end{array}$ & Low & High \\
\hline Distribution & Wide & Wide \\
\hline $\mathrm{CO}_{2}$ Neutral & Yes & No \\
\hline Abrasion to machine & No & Yes \\
\hline $\begin{array}{l}\text { Health risks when } \\
\text { inhaled }\end{array}$ & No & Yes \\
\hline Disposal & Biodegradable & Non-Biodegradable \\
\hline
\end{tabular}

The objective of this study is to provide alternatives for sound absorption using recycled materials that may potentially absorb sound and produce and analyze sound absorbers with the use of recycled materials as a study material.

\section{LITERATURE REVIEW}

Basically, sounds can provide discomfort and sound pollution to humans when something sounds too loud. Sound absorption means the loss of the mechanical energy of the sound when the resulting noise is not reflected back. Given some frequency, the sound absorption frequency reflects its coefficient. For a sound absorbing material, the surface encounters sound waves and this state implies that the fiber absorbs them before producing vibrations. The resulting vibrations will result in a small amount of heat resulting from the friction [1].

Acoustic panels are placed in the room on any surface such as coins, walls and aim to reduce sound waves. Through this study using recycled materials and native fibers such as egg tray, sugar cane and corn skins can further enhance awareness of the use of waste materials as one of the initiatives for sound absorption studies. Sugarcane and corn husk are selected as material in study because it can be recycle to reduce the waste. Aside from being a sound absorber, sugarcane can also be used in the manufacture of particle board, paper, fungus planting and composite steel [11]. Corn husk has high cellulose fiber content so it can be used as raw material for making art [3]. The picture of sugar cane and corn husk are shown in Fig. 1. While the different types of surfaces of the study materials are described in Fig. 2.

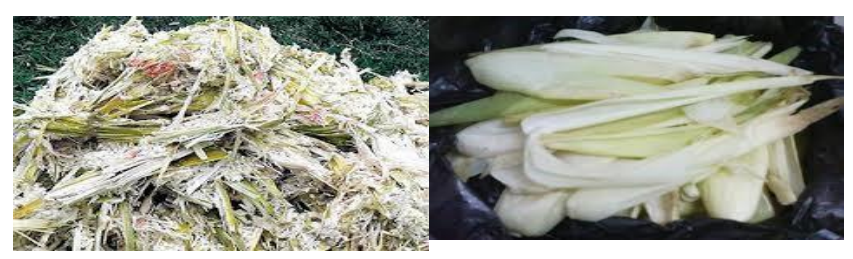

Fig. 1: sugarcane and corn husk

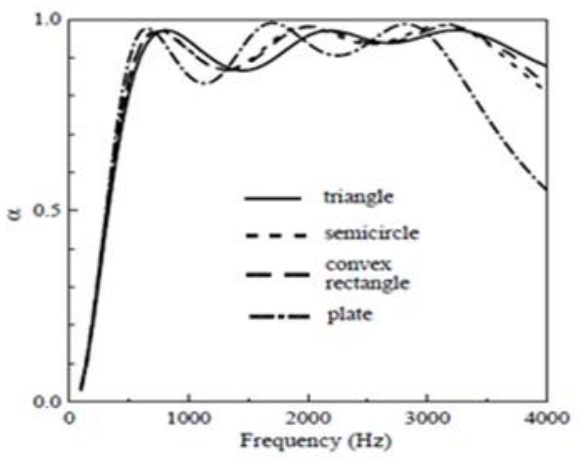

Fig. 2: Differences types of structure in sound absorption (Lee, \& Chen, 2003)

To ensure sound absorption works well, the choice of sound absorption material is important. The structure of an absorption material is important [5]. Studies from Lee and Chen (2003) show the effect of sound absorption panel geometry analyzed based on four types of basic structures are triangles, semi-circles, rectangles and plates. Fig. 4 shows the results of the study where the triangular type structure can absorb sound for high frequency.

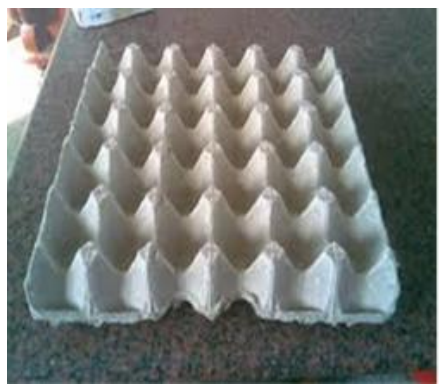

Fig. 3: Egg Tray

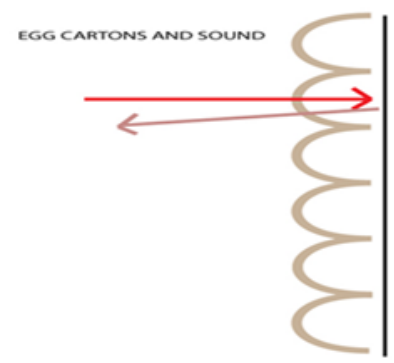

Fig. 4: Sound wave hit the surface of the egg tray Source: (Matt Vaughan, 2012)

Given that egg tray surfaces are uneven in shape and exhibit varying pitch, as seen in Figure 3, they are likely to be broken by sound waves (see Figure 4). It is also worth noting that paper composition is used to make the egg tray, which serves the role of sound absorption.

Published By: Blue Eyes Intelligence Engineering \& Sciences Publication 


\section{MATERIALS AND METHODS}

During the production of the sound absorption panels, sugar cane and corn skin constitutes the basic ingredients. These materials are used as the main absorbent platforms. On the other hand, the panel's base constitutes plywood; with the egg tray acting as a layer. Indeed, the decision to combine these three ingredients is informed by the need to ensure that the sound absorption is not only strengthened but also enhanced.

\section{A. Impedance tube test}

In this test, the selected materials for investigation exhibit $28 \mathrm{~mm}$ and $100 \mathrm{~mm}$ diameter. The preparation of the sample strives to determine the parameter of sound absorption via an impeller test. With the sample introduced at the impeller tube's end, microphones are used to record the reflection energy and the incident energy - in relation to the noise produced by the noise source. The latter process aids in determining the coefficient value of sound absorption for the target or selected material types. The AFD 1001 software is employed for recording the data in the entirety. In the test tube, the apparatus used is shown in Figure 5 below.

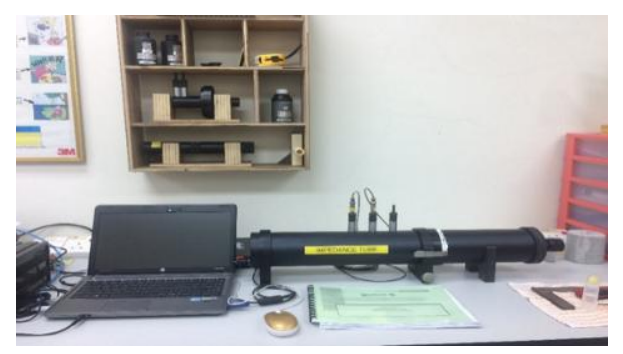

Fig. 5: Impedance Tube Test

\section{1) Sample preparation}

There are three samples that have been produced. The first is a combination of plywood, egg trays and thin fabric. The second combination involves the use of thin fabric, sugar cane, egg tray, and plywood. The latter is a combination of plywood, egg trays, corn skins and thin fabric. Fig. 6 shown the steps in preparing the material for the first sample.

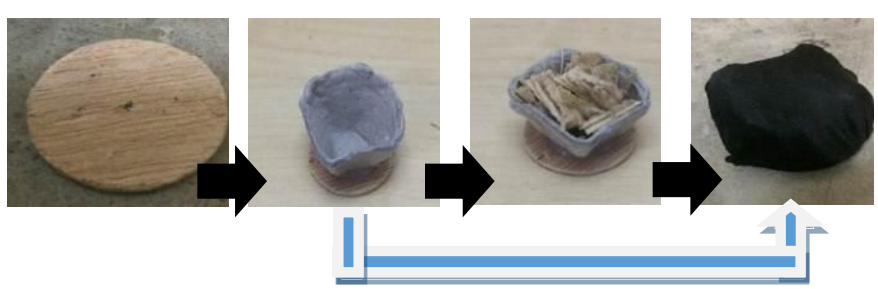

- = Plywood, Egg Tray, Thin Fabric

$\overrightarrow{=}=$ Plywood, Egg Tray, Corn Husk / Sugarcane

Fig. 6: Sample Preparation

\section{B. Reverberation room test}

Given the reverberation chamber, the testing of the panel will be implemented to analysis the resultant state of the

parameter of reverberation time. According to Francesco and Giulio (2005), it is imperative to start by investigating the sample's position. Also, guidelines by the ISO 354 Standard point to the criticality of ensuring that the test materials are not arranged in parallel positions relative to the wall of the room. This precaution is in the minimization of the possible influence of the axis of the wall. A portable analyzer is also used to take measurements in the room, having been complemented by the work of the stationary noise of $01 \mathrm{~dB}$. As indicated in Figure 7, two microphones and the source of the noise sound are introduced and linked to the respective echo recoding and reading times, eventually giving insight into the state of the sound decay. To achieve this stage, the dBBati32 software is employed.

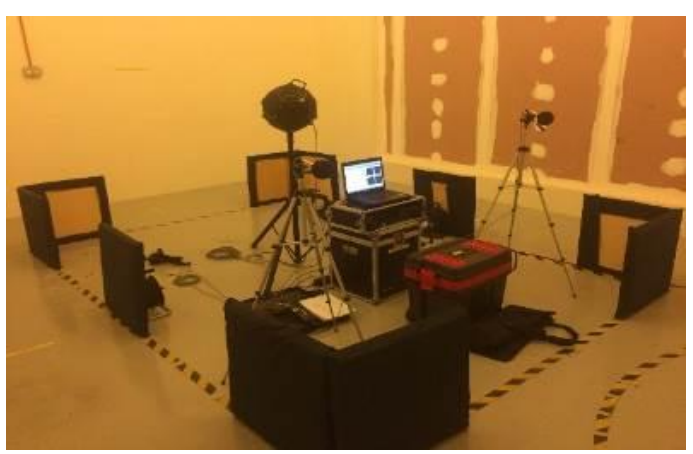

Fig. 7: Test carried out at Acoustic Room

1) Panels preparation

Fig. 8 show the step of sound absorption panel.

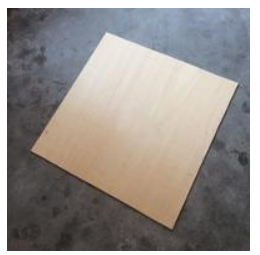

Wood panel was prepared in size $600 \mathrm{~mm} \times 600 \mathrm{~mm}$

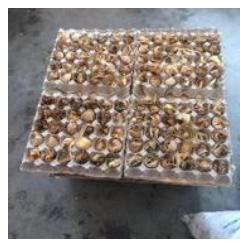

Corn husk or sugarcane is laid as the third layer

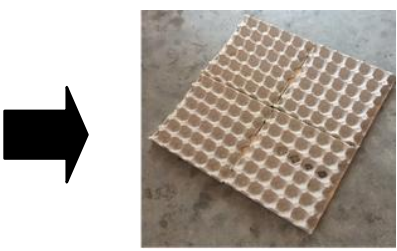

Egg tray was stacked above the surface of panel

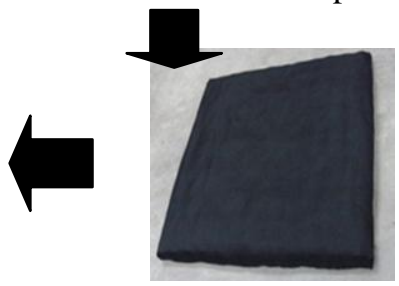

Lastly, the fabric is used as the finishing layer
Fig. 8: Sound absorption panel

Table II illustrates the selected sample's characteristics. Francesco and Giulio (2005) stated that area of absorbent material must be in the range of $15 \%$ to $25 \%$ of the surface area of the reverberant room. From the count, a total of 10 panels of $15 \%$ of the surface area must be prepared. 
Table II: Characteristic of the panel

\begin{tabular}{|c|c|c|c|c|}
\hline $\begin{array}{c}\text { Paramete } \\
\mathrm{r}\end{array}$ & Unit & \multicolumn{3}{|c|}{ Panels } \\
\hline Structure & - & \multicolumn{2}{|c|}{ Sound Absorption Panels } \\
\hline Materials & - & $\begin{array}{c}\text { Egg } \\
\text { Tray }\end{array}$ & $\begin{array}{c}\text { Egg Tray } \\
\& \\
\text { Sugarcan } \\
\text { e }\end{array}$ & $\begin{array}{c}\text { Egg } \\
\text { Tray \& } \\
\text { Corn } \\
\text { Husk }\end{array}$ \\
\hline $\begin{array}{c}\text { Thicknes } \\
\mathrm{s}\end{array}$ & $\mathrm{mm}$ & 50.0 & 50.0 & 50.0 \\
\hline Density & $\mathrm{Kg} / \mathrm{m}^{3}$ & 0.40 & 0.45 & 0.44 \\
\hline $\begin{array}{c}\text { Surface } \\
\text { Area }\end{array}$ & $\mathrm{m}^{2}$ & 0.0036 & 0.0036 & 0.0036 \\
\hline
\end{tabular}

\section{RESULTS AND DISCUSSION}

The experimental study's aim has been to determine the reverberation time (RT), the noise reduction coefficient (NRC), and the sound absorption coefficient $(\alpha)$. In Figure 9, the results obtained relative to the use of different materials are highlighted - in relation to the implementation of the impedance test. From the figure, it is evident that give a low frequency, the selected materials can absorb sound well.

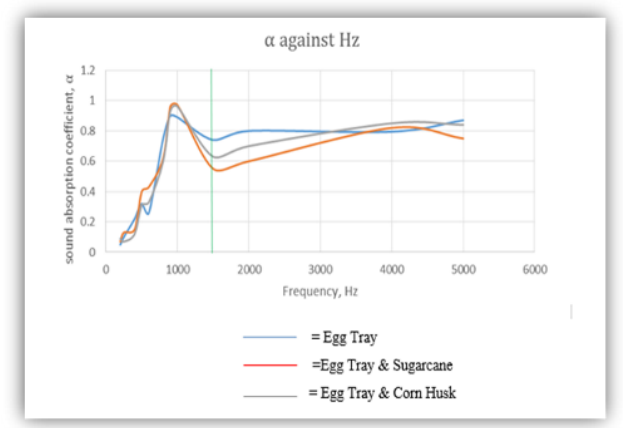

Fig. 9: Sound absorption coefficient ( $\alpha$ ) according to frequency, $\mathrm{Hz}$

Given the frequencies of 2000, 100, 500, and $250 \mathrm{~Hz}$, an average of 0.05 is reported as the NRC value. This value points to the selected materials' sound absorption capacity. Should there be a green line, it suggests a delineation between high frequency and low frequency test. However, an $\mathrm{NRC}$ value that is obtained as 0 implies that the material exhibits promising results relative to sound reflection. If the value is 1 , the material exhibits promising results relative to sound absorption. In this case, an NRC value of 0.5000 was obtained for the case of the egg tray sample. On the other hand, 0.5900 was the NRC value regarding a combination of sugar cane and egg tray. For a combination of the corn husk and egg tray, the NRC value stood at 0.5500 . It is also notable that the NRC values that were obtained in this study were compared with those that had been reported for alternative natural fibers that include sugar cane, grass, and corn, as well as synthetic materials that include the fiberglass board, drapery, plywood, and carpet [3]. In Figure 10, a summary of the comparative analysis of the NRC values is presented.

Based on Fig. 10, glass fibers show high noise reduction coefficients (NRCs). Nevertheless, due to serious health issues if often exposed to this material such as inflammation of the skin, redness, nose and throat irritation indirectly is not a good choice. Not only that, cough, bronchitis, shortness of breath, and also lung disease will occur if humans breathe air filled with glass fiber dust for too long [2]. Therefore, glass fibers are not the best choice despite having a good absorbing ability. From the figure, the egg tray materials produced NRC value of 0.50 and this value is increased with an addition of at the top layer of the egg tray. In addition, the study of egg tray and sugarcane produce good value of NRC compared with other natural materials. However, all natural fiber materials exhibit good absorption characteristic.

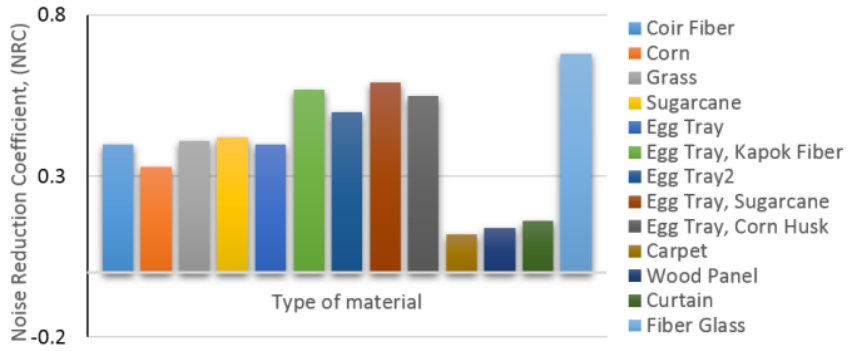

Fig. 10: Comparison between the research materials, natural fibers and synthetic materials.

Regarding the aspect of sound absorption, the characteristics of the sound material do not necessarily play an important role. However, it is important to ensure that the potential loss of the reverberation sound is controlled. Figures 11 and 12 indicate differences (in seconds) in the reverberation times between rooms with panels and empty rooms; with the microphones also placed at different positions. On average, the two experimental results pointed out the existence of significant differences regarding the reverberation sounds, given low frequencies ranging from 1.50 to $1600.00 \mathrm{~Hz}$.

Refer to Fig. 11 and Fig. 12, room with the panel produces a mean short time value of the echo short on both microphones compared to the time of the echo of the room without the panel. Maximum value on microphone 1 for non-paneled rooms is 6.280 seconds at $125 \mathrm{~Hz}$ while maximum value for room with panel gets three different readings according to panel type. The egg tray panel recorded a value of 4.380 seconds at a frequency of $250 \mathrm{~Hz}$. egg tray panel with sugarcane tailings showed a maximum value of 4.210 seconds and the egg tray panel with corn skin recorded an echo time value of 3.990 seconds at a frequency of $250 \mathrm{~Hz}$. Acoustic panel of egg tray with corn skin has the lowest echo time value between the other acoustic panels. 


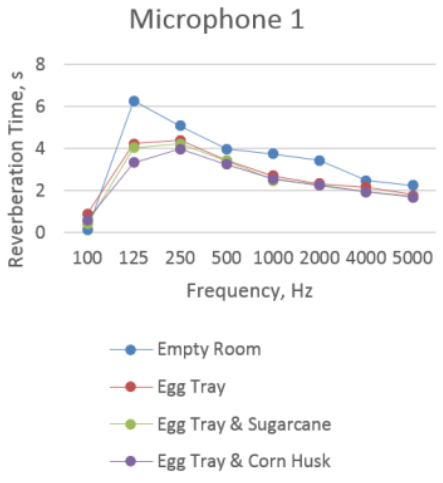

Fig. 11: Reverberation time at Microphone 1

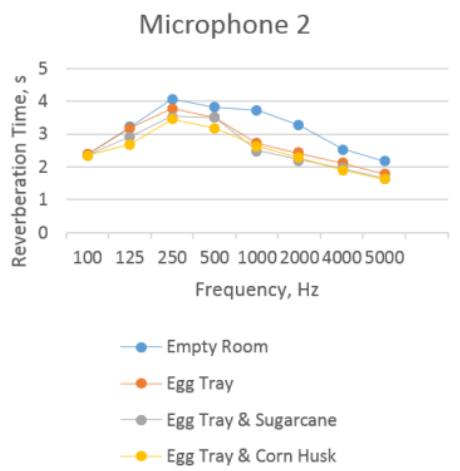

Fig. 12: Reverberation time at Microphone 2

At the microphone 2, the empty room recorded maximum echo time is at a frequency of $250 \mathrm{~Hz}$ which is as much as 4,080 seconds. The egg tray panel records the maximum value of the echoes at a frequency of $250 \mathrm{~Hz}$ as much as 3.780 seconds. Egg tray panel with sugarcane cane takes an echo time of 3,540 seconds at a frequency of $250 \mathrm{~Hz}$. The egg tray panel with corn husk also gives the maximum value of the echo time of 3.450 seconds at a frequency of $250 \mathrm{~Hz}$. This proves that the egg tray panel with corn husk has the highest value of the echoes of the lowest time between the other acoustic panels for the microphone 2 .

\section{CONCLUSION}

In summary, good sound absorption properties were found in experimental conditions that involved combinations of sugarcane materials with egg trays and corn husks with egg trays. Hence, the introduction of the innovative sound absorption panel is seen to attract a state of environmentally-friendly products. In future, there is a need for research studies to focus on other natural fibers and their sound absorption capacity; including banana leaves and skins, grass, and coir fibers; which could be used as layers on egg tray surfaces.

\section{REFERENCES}

1. Cox, T., \& Antonio, J. (2004). Acoustics Absorbers and Diffusors.

2. Fagbemigun, \& Taiwo, K. (2014). Pulp and Paper-Making Potential of Cornhusk. Lagos-Nigeria International Journal of Agri Science Vol 4(4), 209-213.

3. Hosseini, Ayub, Jailani, F, M.N, \& M. (2011). Analysis of coir fiber acoustical characteristics. Applied Acoustics 72(1), 35-42.
4. Koizumi, T., Tsujiuchi, N., \& Adachi, A. (2002). WTT Press, Southampton, UK. High Performance Structures and Composite Book, 127-166.

5. Lee, \& Chen W. (2003). Sound Absorption Properties Of Recycled Polyester Fibrous Assembly Absorbers. AUTEX Research Journal 3(2)

6. Nick, B., \& Thomas,W. (2002). Improved acoustic behavior of interior part of renewable resources in the automotive industry. journal of polymers and the environment, 115-118.

7. Nunez, D. G. (1998). causes and effect of noise pollution. Retrieved from student UK.ask.com/.../causes-and-effect-of-noise-pollution-United-Kingdom

8. SadatniaM, Ebrahimi, G., \& Tajvidi , M. (2008). Proceedings of the 17th World Conference on Nondestructive Testing. Comparing sound absorption characteristic of acoustic board made of Aspen particles and different percentage of wheat and barley straws., 1-6.

9. Slamet. (2002). Tebu. Available: http://warintek.progresio.or.id/tebu/perkebun/warintek/merintisbisnis/pro gresio.html

10. Tipler, P. A. (1998). Physics for Scientists and Engineer Vol 1. Mechanics, Oscillations and Waves and Thermodynamics, London.

11. Wambua, P., J. Ivens, \& I. Verpoest. (2003). Composite Science and Technology. Natural Fibres: Can They Replace Glass In Fibre Reinforced Plastics?, 1259-12646.

12. Wang C. N, \& J. H. Torng. (2001). Experimental study of the absorption characteristic of some porous fibrous materials. applied acoustic, 447-459.

13. Wassilieff, C. (2003). Applied Acoustics 48. 339-356.

14. Yang, H., Kim, D., \& Kim, H. (2003). Bioresource Technology. Rice straw-wood particle composite for sound absorbing wooden construction material, 117-121.

15. Zulkarnain, Z. R., \& J, M. M. (2010). American Journal of Applied Science. 260-264.

\section{AUTHORS PROFILE}

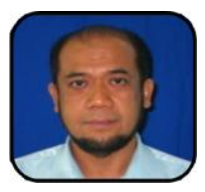

Masiri Kaamin is a Masters holder in Land Surveying (Geomatics), specialty in Geographic Information System. He graduated from Universiti Teknologi Malaysia in the year 1989 (Bachelor of Surveying) and 2001 (Master of Science). Since 2001, he has been involved in publication of more than 80 journals and proceeding articles, books and book chapters as main- and co-authors in various Geomatics and Civil Engineering areas. Of these, 42 are SCOPUS indexed articles. He has been also involved in 25 research grants as main- and co-researcher, funded by the Universiti Tun Hussein Onn Malaysia (UTHM) and Malaysian Ministry of Education. He is a Graduate member of Malaysian Board of Technologies (MBOT). He is recognized as a Professional Technologist (Ts) from MBOT since 2018 under the field of Resource Based, Survey \& Geomatics Technology. He is currently holding a post as Associate Professor in UTHM and keep on fully dedicating in teaching, supervising, research and publication for the sake of current and future generation.

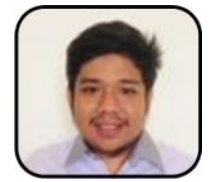

Nur Fadzly Md Zaid is a bachelor degree holder in civil engineering. He graduated as a bachelor holder from University Tun Hussien Onn (UTHM) in year 2018. He is currently continuing his studies at (UTHM) in engineering and vocational education (civil engineering) as a publish an article. post-graduate student. This is the first experience for him to

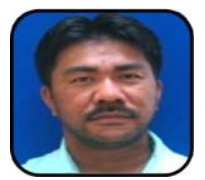

Mohd Effendi Daud is a Doctor of Science in Earth and Environemntal Science, specialty in Applied Geomatics for Tsunami and Earthquake. He graduated from Nagoya University, Japan in the year 2008. Since 2001 , he has been involved in publication of more than 80 journals and proceeding articles, books and book chapters as main- and co-authors in various Geomatics and Civil Engineering areas. Of these, 30 are SCOPUS indexed articles. He has been also involved in 25 research grants as main- and co-researcher, funded by the Universiti Tun Hussein Onn Malaysia (UTHM) and Malaysian Ministry of Education. He is a Graduate member of Malaysian Board of Technologies (MBOT). He is recognized as a Professional Technologist (Ts) from MBOT since 2018 under the field of Resource Based, Survey \& Geomatics Technology. He is currently holding a post as Associate Professor in UTHM and keep on fully dedicating in teaching, supervising, research and 
publication for the sake of current and future generation.

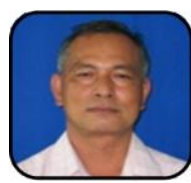

Rosdi Ab. Rahman is a Masters holder in Mechanical Engineering, graduated from the University of Technology Malaysia (UTM) in the year 2001. He received the Bachelor of Engineering, specialty in Power and Machinery from the University of Agriculture Malaysia (UPM) in 1989. He joined the Department of Mechanization, Rubber Research Institute of Malaysia, as a Researcher officer, and Department of Oil \& Gas Engineering, Kuching Polytechnics, Malaysia Ministry of Education, as a Lecturer in 1989 and 1991, respectively. Since December 2001, he has been with the Department of Mechanical Engineering, Centre for Diploma Studies, Universiti Tun Hussein Onn Malaysia (UTHM). Since 2001, he has been involved in publication of more than 40 journals and proceeding articles, books and book chapters as main- and co-authors in various Engineering areas. He has been also involved in 15 research grants as main- and co-researcher, funded by the Universiti Tun Hussein Onn Malaysia (UTHM) and Malaysian Ministry of Education

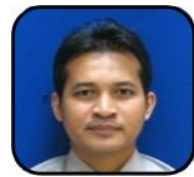

Hairul Mubarak Hassim is a Master holder in Mechanical Engineering. He graduated from University of Manchester Institute Science and Technology (UMIST) in 1999 (Bachelor of Engineering) and from Universiti Tun Hussein Onn (UTHM) in 2014 (Master of Engineering). He had 15 years experiences working as a mechanical engineer before joining UTHM as a lecturer in 2015. His working experiences are in the field of design (R\&D) and manufacturing process (machining, metal forming and injection moulding). Since 2015, he has involved in four research grants as main and co researcher funded by UTHM. His current research interests include palm fatty acid distillate (PFAD) in biodiesel and super critical carbon dioxide $\left(\mathrm{SCCO}_{2}\right)$ in machining.

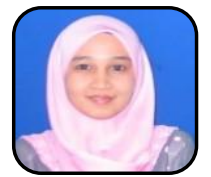

Nor Baizura Hamid is a Bachelor holder in Civil Engineering with Honors which was graduated in 2009 from Universiti Tun Hussein Onn Malaysia. She is currently a Civil Engineering Lecturer in UTHM with 8 years' experience. She has published more than 20 articles in journals and conference proceedings as main author and co-author for the las 5 years. Of these, 15 are SCOPUS indexed articles. She has been also involved in many researches starting from 2013 until now. She has involved in 11 research grants as main- and co-researcher, funded by the Universiti Tun Hussein Onn Malaysia (UTHM) and Malaysian Ministry of Education. She also a Graduate member of Malaysian Board of Engineering (BEM) from 2011. She is currently holding a post as Instructor Engineer in UTHM and keeps on fully dedicating in teaching, supervising, research and publication for the sake of current and future generation.

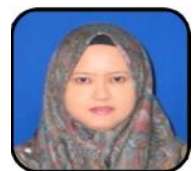

Mardiha Mokhtar is a Masters holder in Civil Engineering graduated from Universiti Tun Hussein Onn Malaysia (UTHM) in 2011. Her field of specialty is Geotechnical Engineering. She was a Civil Engineer at Public Works Department and in 2013, she joined the UTHM as a Lecturer. Since 2012 she has been involved in publication of more than 20 journals and proceeding articles, books and book chapters as main and co-authors and been awarded as Outstanding Paper Award by Academic Research Society of Malaysia in 2018. Since 2015, she has involved in 4 research grants as main and co-researcher, funded by the Universiti Tun Hussein Onn Malaysia (UTHM). Her current research interests include soil stabilization, coastal erosion and UAV applications. Her teaching topic involved Geotechnical Engineering, Drawing Engineering, Static and Dynamic, Mechanics of Materials and Construction Engineering. She is currently a Lecturer in UTHM and associate researcher at Centre of Applied Geomatics for Disaster Prevention (CAGeD), Faculty of Civil and Environmental Engineering, UTHM 